\title{
THE DYNAMICS OF LOCAL LEARNING IN GLOBAL VALUE CHAINS: UMA ANÁLISE CRÍTICA
}

\section{RESUMO}

O livro The dynamics of local learning in global value chains: Experiences form East Asia de Momoko Kawakami e Timothy Sturgeon relata o processo de acumulação de capacidade por várias firmas e setores do Leste da Ásia. Estende e modifica a perspectiva da cadeia global de valor (CGV) existente e apresenta um quadro de referência próprio para explicar como se dá o processo de acumulação em países de industrialização tardia. Contesta a ideia estabelecida na literatura sobre CGV que a possibilidade de acumulação de capacidades e de realização de upgrading é determinada pela estrutura de governança da cadeia. Contrapropõem que o processo de acumulação pode ocorrer mesmo em CGV fortemente coordenadas, se a firma fornecedora perseguir empreendedoramente uma estratégia de aprendizagem que for acompanhada pela estratégia de outsourcing das empresas líderes. Esta resenha apresenta ao leitor conceitos básicos de CGV e resume os capítulos do livro, enfatizando a contribuição teórica e prática de cada um deles. Termina destacando os pontos fortes e fracos do livro e questões que esse sugere para pesquisadores interessados na perspectiva. Os leitores da resenha entenderão o processo pelo qual os setores analisados nos capítulos passaram e as implicações das experiências deles para firmas de países como o Brasil, que almejam se inserir de forma mais competitiva nas CGVs.

Palavras-chave: Cadeias Globais de Valor, Estratégia Internacional, Países Emergentes, Leste da Ásia, Capacidades Tecnológicas.

\section{ABSTRACT}

The book "The dynamics of the local learning in global value chains: Experiences from East Asia, by Momoko Kawakami and Timothy Sturgeon describes the process of capability accumulation by several firms and sectors of East Asia. It extends and modifies the existing perspectives of global value chain (GVC) and presents its own frame of reference to explain how the process of accumulation in late industrializing countries occur. It challenges the idea established in the literature on GVC that the possibility of accumulation of capabilities and functional upgrading is determined by the governance of the value chain. It argues that the process of accumulation can occur even in highly coordinated GVCs, if the supplier pursues entrepreneurially a learning strategy that is accompanied by the outsourcing strategy of the leading companies of the GVC. This review introduces the reader to the basic concepts of GVC and summarizes the chapters of the book, emphasizing the theoretical and practical contribution of each one of them. It closes highlighting the strengths and weaknesses of the book and the issues it suggests to researchers interested in the subject. Readers of the review will understand the process that the sectors analyzed in chapters went through and the implications of these experiences for firms in countries like Brazil, which aims to insert themselves more competitively in GVCs.

Keywords: Global Value Chains, International Strategy, Emerging Countries, East Asia, Technological Capabilities.

\footnotetext{
${ }^{1}$ Escola Superior de Propaganda e Marketing - ESPM, Brasil

E-mail: iavrichir@yahoo.com

${ }^{2}$ Escola Superior de Propaganda e Marketing - ESPM, Brasil

E-mail: baraujo@espm.br

${ }^{3}$ Escola Superior de Propaganda e Marketing - ESPM, Brasil

E-mail:wramiro@espm.br
} 
The Dynamics of Local Learning in Global Value Chains: Uma Análise Crítica

\section{INTRODUÇÃ̃O}

Países de industrialização tardia, como o Brasil e a maioria das economias emergentes, têm dificuldade de exportar bens de alto valor agregado e que requerem competências tecnológicas sofisticadas. Muitos autores sustentam que é praticamente impossível, para empresas desses países, que elas consigam desenvolver essas competências e apropriem parcelas significativas do valor gerado nas cadeias globais de valor (CGV) nas quais estão inseridas. A dificuldade em fazer isso seria ainda maior quando uma empresa da cadeia, em geral de país desenvolvido, detém muito poder nessa cadeia e exerce papel forte de governança nela.

Momoko Kawakami e Timohty J. Sturgeon, num livro relativamente recente (KAWAKAMI \& STURGEON, 2011), reúnem várias evidências de que é possível, para setores econômicos e empresas de países de desenvolvimento tardio, fazerem exatamente isso: desenvolverem competências tecnológicas sofisticadas e produzirem localmente, se não exportarem, produtos de alto valor agregado.

Entendemos que o livro, por força das experiências bem-sucedidas de países emergentes do Leste da Ásia as quais relata e da sistematização dessas experiências que faz, traz informações importantes para pesquisadores, profissionais e formuladores de políticas do Brasil e outros países emergentes. São essas informações e sistematizações que resumimos nessa resenha, na qual também adiantamos as implicações que vemos das experiências ocorridas no Leste da Ásia para os três públicos acima.

Essa resenha se compõe de três seções além dessa introdução: na primeira apresentamos rápido histórico da perspectiva teórica da CGV e dos principais conceitos dessa perspectiva, de forma a permitir que o leitor não familiarizado com os conceitos básicos da CGV possam entender a resenha; na segunda resumimos, capítulo a capítulo, as experiências que o livro relata; na terceira e última, destacamos as implicações das informações que o livro traz, discutimos em que medida os aprendizados que os autores do livro destacam são transferíveis ou não para as condições brasileiras e, transcendendo um pouco os limites da resenha, sugerimos temas e questões de pesquisa promissores para pesquisadores brasileiros usando a perspectiva da $\mathrm{CGV}$.

\section{CADEIAS GLOBAIS DE VALOR. DO QUE ESTAMOS FALANDO}

O termo cadeia global de valor e a abreviatura CGV diz respeito a coisas interligadas, mas diferentes, o que gera alguma confusão. O termo nos remete a um fenômeno e a uma metodologia de análise ou quadro de referência teórico. Enquanto fenômeno, refere-se ao fato de que, com a globalização, diminuição da intensidade das barreiras tarifárias e barateamento das comunicações e transporte entre países, as empresas, principalmente multinacionais, em geral com o objetivo de reduzir custos, passaram a distribuir entre vários países, a execução das atividades que exercem e a origem dos bens e serviços que adquirem.

A dispersão geográfica da produção de bens e serviços, ao qual alguns se referem como slicing, fatiamento, fez com que a produção de um bem, antes concentrada num único local ou pelo menos num único país, passe a ser realizada em múltiplas etapas, ou elos de um encadeamento de atividades distribuídas entre muitas empresas em vários países. As reuniões desses elos formam cadeias que, por estarem localizadas em diferentes países, são globais, daí o termo e abreviatura CGV. Para se ter uma ideia da dimensão desse fenômeno, Pascal Lamy, por duas vezes ex-diretor geral da Organização Mundial do Comércio (OMC) estima que, atualmente, cerca de $40 \%$ do conteúdo exportado por um país é composto por bens e serviços que importa e que, portanto, a contabilidade do comércio internacional está grosseiramente superestimada, requerendo urgente revisão de como é feita. Segundo ele, esse percentual, que era $20 \%$ há 20 anos, será $60 \%$ daqui a outros 20 (LAMY, 2014).

Mas, o termo também se refere a uma metodologia de análise, surgida no início dos anos 1990, que busca estudar esse fenômeno, principalmente sob uma perspectiva desenvolvimentista, isso é, buscando entender como e porque essa distribuição de atividades possibilita ou não às empresas, principalmente de países emergentes, se apropriarem de parcelas maiores do valor gerado ao longo da cadeia. E busca, também, entender como o fato das empresas fazerem isso influencia o desenvolvimento dos países emergentes nos quais elas estão situadas. A CGV, enquanto metodologia de análise descreve toda a gama de atividades que as empresas e os trabalhadores executam para trazer um produto ao mercado, desde a sua concepção até o uso final e além. Isso inclui atividades como design, produção, marketing, distribuição e suporte ao consumidor final (GEREFFI \& FERNANDEZ-STARK, 2011).

$\mathrm{O}$ entendimento das cadeias globais de valor, através da metodologia de análise da $\mathrm{CGV}$, permite aos profissionais e aos formuladores de políticas entenderem o contexto competitivo em que as empresas que lhes interessam estão inseridas de forma mais ampla que as metodologias anteriores. Ao incluir no quadro a análise das relações entre empresas situadas em diferentes países, e das relações de poder entre essas empresas, a CGV favorece a formulação de políticas nacionais e estratégias apropriadas ao nível de desenvolvimento das empresas e industrias nacionais. Os gargalos existentes nas cadeias de valor nacionais 
The Dynamics of Local Learning in Global Value Chains: Uma Análise Crítica

são diagnosticados, as questões que se pode esperar que as empresas resolvam sozinhas emergem e os pontos em que o governo precisa atuar ficam claros (SCHMITZ, 2005).

Dois conceitos são centrais para o entendimento da metodologia, seu alcance e a questão das relações de poder entre empesas e indústrias nacionais, elos das cadeias, aos quais aludimos no parágrafo acima: Os conceitos de governança das cadeias e de upgrading ao longo delas.

\subsection{Governança das cadeias}

A questão da governança das cadeias surge na medida em que a produção passa a ser fragmentada através de áreas geográficas e entre firmas e deixa de sêlo pela gerência de uma única fábrica ou organização. Nessas novas circunstâncias, como os preços de transferência entre os elos são determinados? Como os padrões técnicos, que permitem que as montagens de componentes se deem de forma eficiente e segura, são estabelecidos? Como os desenvolvimentos de novos produtos, que exigem integração entre diferentes elos, acontecem? Como, enfim, as cadeias são coordenadas? Todas essas questões, que eram resolvidas antes pelas matrizes ou através de processos de negociação entre essas e suas filiais, num processo de governança hierárquica, burocrática, passam a sê-lo através de outras formas. Que formas são essas?

Possivelmente, o artigo mais importante para se entender o conceito de governança é o de Gereffi, Humphrey e Sturgeon (2005). Ele tem pelo menos três vezes mais citações no Web Of Science, o indexador de artigos mais conceituado no meio acadêmico, do que o segundo mais citado. $\mathrm{O}$ artigo é tão conhecido que virou sigla. Os pesquisadores da área se referem a ele como o GHS!

No artigo, os autores, usando o referencial dos custos de transação, desenvolvem uma teoria sobre a governança das cadeias. Eles explicam o conceito de governança, desenvolvem uma tipologia dos tipos de governança que ocorrem em cadeias globais de valor e sustentam que três fatores determinam o tipo de governança que ocorrerá na cadeia. São eles: A complexidade das informações referentes a produtos e processos necessários para sustentar uma transação particular; a codificabilidade dessa informação ou seja, o quanto a informação necessária para a realização da transação pode ser transmitida eficientemente sem investimentos específicos das partes nessa transmissão e a capacidade dos fornecedores (os exportadores) em relação aos requisitos da transação. Humphrey e Schmitz (2000) desenvolveram outra taxonomia de tipos de governança apoiada nos mesmos conceitos (e que tem a seu favor o fato de ter sido mais usada para fins empíricos) bem menos citada.

Gereffi, Humphrey e Sturgeon (2005) postulam que, a bem da concisão e parcimônia, os tipos de governança podem ser reduzidos a cinco: Mercado; Modular; Relacional; Cativa e Hierárquica. A relação entre os determinantes, o tipo de governança e o grau de assimetria de poder entre o coordenador da cadeia e os demais elos dela, estão resumidos na Figura 1 e explicados na sequência.

Figura 1. Determinantes-Chave do tipo de governança das CGV

\begin{tabular}{|c|c|c|c|c|}
\hline $\begin{array}{c}\text { Tipo de } \\
\text { governança }\end{array}$ & $\begin{array}{l}\text { Complexidade das } \\
\text { transações }\end{array}$ & $\begin{array}{l}\text { Codificabilidade } \\
\text { das transações }\end{array}$ & $\begin{array}{c}\text { Capacidade dos } \\
\text { fornecedores }\end{array}$ & $\begin{array}{c}\text { Nível de assimetria de } \\
\text { poder }\end{array}$ \\
\hline Mercado & Baixo & Alto & Alto & Baixo \\
\hline Modular & Alto & Alto & Alto & \multirow[t]{3}{*}{$\uparrow$} \\
\hline Relacional & Alto & Baixo & Alto & \\
\hline Cativa & Alto & Alto & Baixo & \\
\hline Hierárquica & Alto & Baixo & Baixo & Alto \\
\hline
\end{tabular}

Fonte: (GEREFFI; HUMPHREY; STURGEON, 2005)

\subsubsection{Mercado}

Quando as transações são facilmente codificáveis, as especificações dos produtos são relativamente simples e os fornecedores têm a capacidade de fazer os produtos com pouca ajuda dos compradores, o custo de mudança para novos parceiros é baixo para ambas as partes e o tipo de governança que se estabelece tende a ser semelhante ao que acontece num mercado de concorrência perfeita. Os vínculos mercadológicos tendem a ser transitórios, e o foco da relação entre fornecedores e empresas que fazem o outsourcing é o preço.

\subsubsection{Modular}

Quando a complexidade dos produtos é alta, mas é possível codificar as especificações, o tipo de governança tende a ser modular. Isso acontece, por exemplo, quando normas técnicas reduzem a variação dos componentes ou quando os fornecedores têm competência para fornecer conjuntos completos ou módulos, o que reduz a necessidade de controle direto que o comprador precisa exercer. Por causa da codificação, informações complexas podem ser trocadas com pouca coordenação explícita e o custo de 
The Dynamics of Local Learning in Global Value Chains: Uma Análise Crítica

trocar de parceiros é quase tão baixo quando a coordenação do tipo mercado.

\subsubsection{Relacional.}

Esse tipo de governança acontece quando as especificações não podem ser codificadas, as transações são complexas e as capacidades dos fornecedores são altas. Nele, uma relação de mutua dependência entre fornecedor e comprador se desenvolve. Isso ocorre porque conhecimento tácito precisa ser trocado entre fornecedores e compradores e porque os compradores se sentem motivados a fazer outsourcing para se beneficiar das competências dos fornecedores. Nesse tipo de cadeias, o custo de trocar de parceiros tende a ser alto.

\subsubsection{Cativa.}

Quando a possibilidade de codificar e a complexidade dos produtos são altas e a capacidade dos fornecedores é baixa, a governança tende a ser do tipo cativa. Isso acontece porque o comprador controla muito o fornecedor e transmite capacidades de produto e processo para o mesmo. Os compradores protegem do oportunismo do fornecedor promovendo a dependência dos fornecedores com relação a eles e confinando-os a funções simples, como montagens, e preservando as complexas, como design, logística e desenvolvimentos tecnológicos, para si.

\subsubsection{Hierárquica.}

Quando as especificações dos produtos não podem ser codificadas, os produtos são completos e a capacidade dos fornecedores baixa, os compradores tendem a produzir os produtos internamente, mesmo que façam isso em outros países. Nesse caso, o fazem através de filiais e exercem controle burocrático.

\subsection{Upgrading}

Apesar de a governança ser o conceito chave da CGV, o de upgrading é quase tão importante quanto ele, porque muitos dos pesquisadores que usam a $\mathrm{CGV}$ como referencial têm foco forte em desenvolvimento (GEREFFI, 2014). O upgrading consiste na aquisição de capacidades que permitam às firmas executarem atividades que têm maior margem e são mais difíceis de replicar (NAVAS-ALEMÁN, 2011). A mesma autora elabora uma taxonomia de tipos de upgrading baseada em Humphrey \& Schmitz (2000), que foi útil numa pesquisa sobre a exportação de granito no Brasil (MACLENNAN; AVRICHIR; FIGUEIREDO, 2015). A taxonomia não difere substancialmente de outras sobre o mesmo tema: (HUMPHREY \& SCHMITZ, 2002) e (KAPLINSKY; MORRIS, 2003).

\subsubsection{Upgrading de processo}

Diz respeito a melhorias no sistema de produção. Envolve novas máquinas, programas de qualidade e gestão da produção, redução de tempos de entrega e, de forma geral, significa ter formas mais eficientes de transformar entradas em saídas.

\subsubsection{Upgrading de produtos}

Envolve a introdução de novos produtos, mudança de desenhos e produção de saídas mais sofisticadas.

\subsubsection{Upgrading funcional}

Corresponde a mover-se para estágios diferentes além da produção, tais como o branding e o marketing.

\subsubsection{Upgrading de Cadeia}

Constitui a mudança para uma nova cadeia de valor, utilizando a experiência adquirida na cadeia anterior para a fabricação de novos produtos e serviços.

\section{COMO O LIVRO ESTÁ ESTRUTURADO E QUAIS TESES ELE SUSTENTA}

O livro está estruturado em sete capítulos mais uma introdução e uma conclusão. A conclusão é muito breve, pouco mais de uma página, e se limita a resumir as principais ideias. Não permite entender do que o livro trata e aprender as suas principais teses. Mas a introdução é bem mais detalhada e informativa: descreve claramente o objetivo do livro, traz um resumo da perspectiva da $\mathrm{CGV}$, apresenta o quadro de referência do livro, contrasta suas teses centrais com as que predominam entre os autores consagrados da perspectiva e resume os capítulos. Permite ter uma boa ideia do conteúdo que o livro apresenta. A seguir, resumimos o conteúdo do livro, obedecendo a sequência com que é apresentado.

$\mathrm{Na}$ introdução de Value chain dynamics and capability formation by latecomer firms in East Asia, o autor chama a atenção para as diferenças entre a perspectiva do livro e a predominante na CGV. Destaca que o clássico artigo de Gereffi, Humphrey e Sturgeon de 2005, teve o mérito de oferecer um quadro de referência para analisar a governança e a assimetria de poder nas CGVs, mas, como consequência indesejada, levou pesquisas posteriores a se concentrarem no comprador e nas empresas líderes, deixando o fornecedor, em geral exportador de países de industrialização tardia, algo de lado. Claramente, afirma a autora da introdução, "é necessário um quadro de referência que coloque o crescimento da empresa de industrialização atrasada no centro da análise" (p. 4). 
The Dynamics of Local Learning in Global Value Chains: Uma Análise Crítica

A autora, na introdução, afirma que as hipóteses de (GEREFFI; HUMPHREY; STURGEON, 2005) são deterministas, na medida em que sustentam que variáveis estruturais determinam a governança da CGV. Os resultados das pesquisas apresentadas no livro teriam demonstrado que as empresas fornecedoras podem alterar as relações de poder nas cadeias, se tiverem estratégias diferenciadas de aprendizagem e conseguirem, em função disso, acumular capacidades, principalmente tecnológicas. Haveria espaço, portanto, para a intensão e a orientação empreendedora do fornecedor em interferir na relação de governança. Essa seria mais dinâmica do que na teoria apresentada por Gereffi, Humphrey e Sturgeon (2005) - não por acaso a palavra dinâmica aparece no título do livro. No modelo proposto, a capacidade dos fornecedores deixa de ser uma variável independente, para se tornar a variável dependente.

No modelo, a capacidade dos fornecedores locais nas CGVs é determinada pela interação entre as estratégias de aprendizagem das empresas dos países de industrialização tardia e as estratégias de outsourcing das empresas dos países desenvolvidos. Essas duas estratégias são, por sua vez, sujeitas a dois fatores causais, a complexidade/codificabilidade das transações envolvidas e o ambiente institucional e o contexto local em que as empresas estão situadas. A representação gráfica do modelo está na Figura 2.

Figura 2. O modelo de Kawakami e Sturgeon

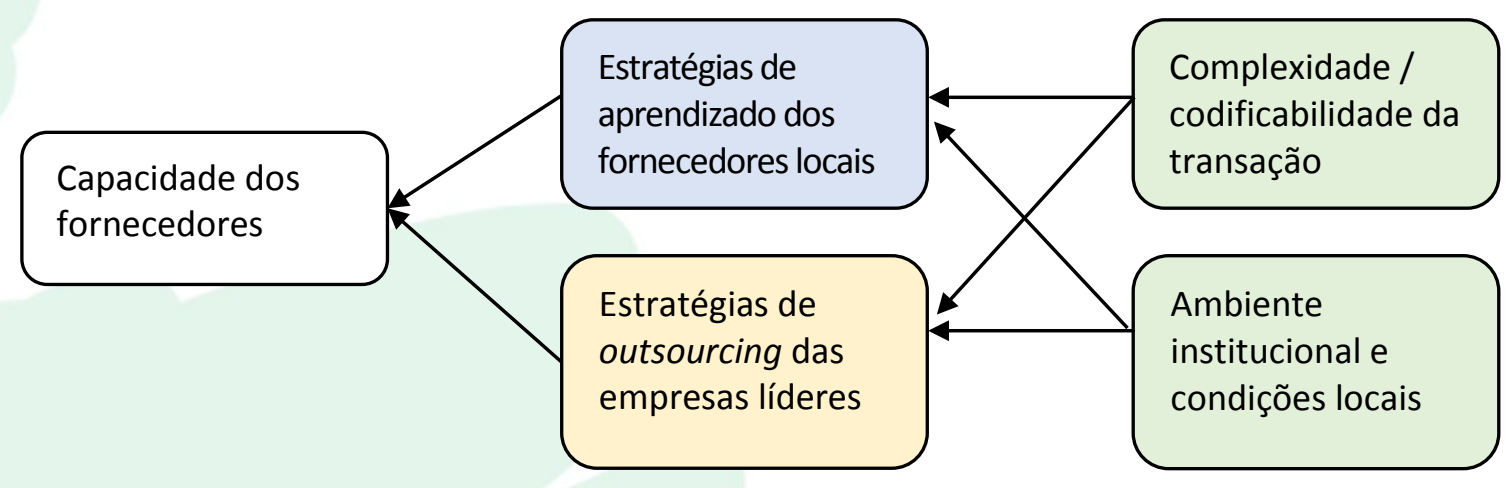

Fonte: Kawakami e Sturgeon, 2011. Traduzido pelos autores.

Os autores do livro definem capacidade do fornecedor como sendo o conjunto dos recursos intangíveis, específicos da firma, localmente situados e os ativos de conhecimento baseados na experiência. Essas capacidades abarcam as habilidades de gerar e gerenciar as mudanças tecnológicas requeridas para estruturar e integrar o feixe de recursos e habilidades da firma, de forma que se adaptem às mudanças externas (p. 5).

O capítulo 1, Inter-firm dynamics in notebook $P C$ value chains and the rise of Taiwanese original design manufacturing firms, relata a bem-sucedida história da aquisição de capacidades pela indústria de notebooks de Taiwan, que em 2008 chegou a responder por $92 \%$ da fabricação mundial daquele produto. Esse sucesso foi fruto da conjugação de dois fatores, em correspondência com o modelo que orienta o livro: de um lado, o outsourcing da fabricação, feito principalmente por empresas americanas e japonesas e, de outro, da exploração pelas empresas taiwanesas da oportunidade representada por essa política de outsourcing, para aumentarem suas capacidades e consolidarem suas posições como fornecedores dominantes.

No final dos anos 90, a Intel adotou a estratégia de incorporar chips e funções em uma única placa, fornecendo solução completa, turnkey, aos clientes. Essa estratégia reduziu barreiras de entrada, o que possibilitou a produção de notebooks por parte de vários novos fabricantes que competiram entre si e derrubaram os preços dos notebooks, fazendo com que fabricantes japoneses e americanos tivessem seus lucros diminuídos.

Os fabricantes americanos, como Dell, Gateway e Compaq, reagiram rápido, terceirizando a produção para empresas taiwanesas, enquanto concentravam seus esforços na concepção do produto, marketing e distribuição. Como as empresas de marca transferiram atividades de valor agregado, passo a passo, para empresas taiwanesas, ocorreu um fluxo intensivo de conhecimento das empresas líderes americanas e japonesas para os fornecedores taiwaneses, no final dos anos 90. Equipes de engenheiros foram enviadas para monitorar e treinar os fornecedores em pesquisa e desenvolvimento, na aquisição de peças e na gestão da produção, dentre outras atividades. Transferência ainda mais intensiva de tecnologia e know-how ocorreu quando as empresas líderes começaram a solicitar serviços de desenvolvimento de produto.

Ao se apropriarem das tecnologias e competências transferidas de várias empresas de notebook e da Intel, no final dos anos 90, fabricantes de 
The Dynamics of Local Learning in Global Value Chains: Uma Análise Crítica

Taiwan obtiveram conhecimento multifacetado de produto, capacidade de produção em massa e de logística, que sustentaram sua ascensão como fornecedores completos de produtos e serviços. A intensa competição entre os fabricantes por pedidos maiores e mais rentáveis conduziu o ritmo deste processo de aprendizagem.

Servir a diferentes tipos de clientes de diferentes mercados (Estados Unidos, Europa, Japão, etc.) e de distintos segmentos de produtos (desde qualidade inferior até superior) expôs os produtores taiwaneses à ampla variedade de tecnologias e informações de mercado. Exigiu deles acomodação a diferentes tipos de requisitos e forçou a aceleração no ritmo de seu aprendizado.

Enquanto alguns fornecedores, como Quanta Computer e Compal Electronics, perseguiram agressivamente a diversificação dos clientes, outras empresas (por exemplo, Inventec e Arima) escolheram tornarem-se fornecedores semicativos dos grandes compradores. Ao interagir com vários clientes, Quanta e Compal obtiveram acesso a informações adicionais de mercado e adquiriram uma vasta gama de capacidades tecnológicas, que lhes propiciou, na fase seguinte, quando o governo permitiu investimentos das empresas taiwanesas na China, a aquisição de capacidades ainda mais amplas. No final da década de 2000, o nível de colaboração entre engenheiros da Intel e empresas de Taiwan se acelerou e consolidou estas últimas na posição mais importante da cadeia CGV de notebooks.

Embora enfatizando que a dinâmica do desenvolvimento da indústria mundial de notebooks está de acordo com o modelo geral que sustenta o livro, a autora destaca três outras "agendas" para pesquisas futuras: 1. Contrariando a tendência dos estudos usando a perspectiva da $\mathrm{CGV}$, de focar uma relação de empresa diádica entre empresa líder e fornecedor, o caso em questão só pode ser entendido a partir de três atores: os fabricantes americanos e japoneses, a Intel e os fornecedores taiwaneses. Convida, portanto a estudar cadeias de governança complexas e diversificadas; 2. Taiwan contou com "enxame" de fabricantes com alto nível de vigor empreendedor. Isso sugere considerar seriamente as condições sociais e econômicas que inibem ou estimulam as firmas de países de industrialização tardia a aproveitarem as oportunidades de aprendizagem oferecidas pelas CGVs; 3. As empresas taiwanesas aproveitaram as capacidades desenvolvidas com os notebooks, para entrar em novas linhas de produtos, usando outras plataformas tecnológicas, principalmente smartphones. Esse tipo fenômeno também é um promissor campo de pesquisa em CGV.

No capítulo 2, Value chain creation and reorganization: The growth path of China's mobile phone handset industry, Ken Imai, pesquisador sênior do Jetro e Jing Ming Shiu, doutorando da Universidade de Tóquio, analisam a dinâmica da indústria chinesa dos seus primórdios até 2007, quando representou $47,8 \%$ da produção mundial. A contribuição dos autores é analisar como as empresas locais chegaram a acumular capacidades, que vão do projeto de produtos a desenvolvimento de plataformas tecnológicas. Os autores também pontuam as características do mercado local que permitiram às empresas locais fazerem upgrading, sem se subordinar a empresas líderes de CGVs.

Os autores sustentam que a possibilidade de criação da indústria chinesa foi dada pela combinação de várias condições: $\mathrm{O}$ tamanho do mercado chinês, a fragmentação desse mercado, o grande suprimento de engenheiros disponível, a abundância de empreendedores prontos a começar suas próprias empresas e a modularidade das tecnologias oferecidas por vendedores de plataforma.

O tamanho do mercado chinês foi determinante, na fase inicial da indústria, para fazer com que empresas multinacionais, principalmente a Nokia e a Motorola, investissem no país, apesar das restrições e controles impostos pelo governo à essas empresas. A diversidade propiciou a fabricantes locais a possibilidade de explorar áreas rurais e pequenas cidades, que não eram atendidas pelos grandes distribuidores nacionais. Esses fabricantes combinaram o desenvolvimento de interfaces que atendiam as preferências desse público com terceirização de atividades de desenvolvimento e produção e alcançaram sucesso extraordinário no final da década de 1990.

Nos anos 1990, com o surgimento da tecnologia GSM para aparelhos celulares, a tecnologia complexa da telecomunicação tornou-se encapsulada, ou modular. Essa modularidade permitiu às firmas chinesas entrarem no negócio de desenvolvimento de aparelhos celulares, apesar das suas fragilidades tecnológicas. Com o aprendizado adquirido, com o apoio institucional do governo chinês e com a disponibilidade de recursos humanos em engenharia eletrônica, as firmas locais rapidamente evoluíram seu nível de capacidade. Aprenderam a desenvolver produtos adequados aos consumidores chineses e passaram a atender, com aparelhos produzidos localmente, cerca de $50 \%$ do mercado local.

Os autores destacam como principal aprendizado do caso que, em países com grandes mercados internos e as outras condições que existiram na China no período descrito, o acesso às $\mathrm{CGVs}$ controladas por multinacionais não é a única alternativa para a realização de upgrading industrial. Essas alternativas são mais plausíveis na medida em que a tecnologia complexa se torna encapsulada e pode ser adquirida, ou como pacote de tecnologia ou como módulos que são integrados e montados localmente. A competitividade das empresas locais é favorecida, nessas situações, pelo conhecimento das condições locais, se o mercado local, além de grande for diversificado. As implicações do caso para países emergentes como o Brasil são evidentes.

O terceiro capítulo, Value chain dynamics and local suppliers' capability building: An analysis of the 
The Dynamics of Local Learning in Global Value Chains: Uma Análise Crítica

Vietnamese motorcycle industry (FUJITA, 2011) descreve o também explosivo crescimento das vendas de motocicletas no Vietnam no período 1998 a 2008 e as consequências para a capacidade das montadoras e fornecedores de peças locais. Nesse período, as vendas saltaram de cerca de 500 mil para mais de 2,5 milhões de motos por ano e o número de fornecedores locais passou de cerca de 30 para mais de 80 . O conteúdo local, que era $20 \%$, chegou perto de $60 \%$.

Figura 3. Matriz de Capacidades para analisar a competência de fornecedores de motocicletas

\begin{tabular}{|c|c|c|c|c|}
\hline & \multicolumn{4}{|c|}{ Função da empresa } \\
\hline Nível de & Pré-produção & Produ & ção & Pós-produção \\
\hline Capacidade & Planejamento & Equipamentos & Gestão de produção & Marketing \\
\hline Operacional & $\begin{array}{l}\text { Replicação de } \\
\text { produtos existentes } \\
\text { no mercado } \\
\text { doméstico ao recriar } \\
\text { design. }\end{array}$ & $\begin{array}{l}\text { Operações básicas de } \\
\text { maquinários e } \\
\text { equipamentos, } \\
\text { matrizes, moldes, } \\
\text { gabaritos e ferramentas } \\
\text { para processar } \\
\text { componentes ao nível } \\
\text { requerido no mercado } \\
\text { local. }\end{array}$ & $\begin{array}{l}\text { Rotinas de gestão } \\
\text { de produção } \\
\text { requeridas no } \\
\text { mercado local. }\end{array}$ & $\begin{array}{l}\text { Rotina de métodos } \\
\text { de marketing e } \\
\text { ações comerciais. }\end{array}$ \\
\hline Assimilativo & $\begin{array}{l}\text { Replicação de } \\
\text { produtos existentes } \\
\text { no mercado } \\
\text { internacional ao } \\
\text { recriar design. }\end{array}$ & $\begin{array}{l}\text { Desenvolvimento de } \\
\text { componentes, } \\
\text { matrizes, moldes, } \\
\text { gabaritos e } \\
\text { ferramentas para } \\
\text { processar } \\
\text { componentes ao nível } \\
\text { requerido no mercado } \\
\text { internacional. } \\
\text { Manutenção de } \\
\text { maquinários e } \\
\text { equipamentos, } \\
\text { matrizes, moldes, } \\
\text { gabaritos e } \\
\text { ferramentas. }\end{array}$ & $\begin{array}{l}\text { Manutenção da } \\
\text { estabilidade } \\
\text { produtiva, } \\
\text { suprindo os níveis } \\
\text { requeridos por } \\
\text { consumidores } \\
\text { internacionais. }\end{array}$ & $\begin{array}{l}\text { Adoção e } \\
\text { melhoramento dos } \\
\text { métodos de } \\
\text { marketing e ações } \\
\text { comerciais. }\end{array}$ \\
\hline Adaptativo & $\begin{array}{l}\text { Fazer melhorias } \\
\text { originais para os } \\
\text { produtos existentes, } \\
\text { de forma a } \\
\text { prevalecer entre os } \\
\text { produtores locais. }\end{array}$ & $\begin{array}{l}\text { Fazer melhorias } \\
\text { originais para a } \\
\text { maquinaria e } \\
\text { equipamentos } \\
\text { existentes, de forma a } \\
\text { prevalecer entre os } \\
\text { produtores locais. }\end{array}$ & $\begin{array}{l}\text { Fazer melhorias } \\
\text { originais nas práticas } \\
\text { de gestão de } \\
\text { produção } \\
\text { predominantes entre } \\
\text { produtores locais. }\end{array}$ & $\begin{array}{l}\text { Fazer melhorias } \\
\text { originais para os } \\
\text { métodos de } \\
\text { marketing } \\
\text { predominante entre } \\
\text { os produtores } \\
\text { locais; desenvolver } \\
\text { marcas } \\
\text { reconhecidas no } \\
\text { mercado nacional. }\end{array}$ \\
\hline Inovativo & $\begin{array}{l}\text { Planejamento e } \\
\text { concepção de novos } \\
\text { produtos com } \\
\text { elementos significativos } \\
\text { de originalidade e } \\
\text { novidade em } \\
\text { comparação com os } \\
\text { produtos existentes que } \\
\text { prevalecem no mundo. }\end{array}$ & $\begin{array}{l}\text { Concepção e } \\
\text { desenvolvimento de } \\
\text { novas máquinas e } \\
\text { equipamentos com } \\
\text { elementos } \\
\text { significativos da } \\
\text { originalidade e } \\
\text { novidade em relação a } \\
\text { máquinas e } \\
\text { equipamentos } \\
\text { existentes no mundo. }\end{array}$ & $\begin{array}{l}\text { Estabelecimento de } \\
\text { sistemas de gestão } \\
\text { de produção, de } \\
\text { modo a atingir o } \\
\text { nível mais alto do } \\
\text { mundo em gestão } \\
\text { de produção. }\end{array}$ & $\begin{array}{l}\text { Novos métodos de } \\
\text { marketing com } \\
\text { elementos } \\
\text { significativos de } \\
\text { originalidade e } \\
\text { novidade para } \\
\text { explorar novos } \\
\text { mercados no } \\
\text { exterior; } \\
\text { Desenvolvimento } \\
\text { de marcas } \\
\text { reconhecidas } \\
\text { internacionalmente. }\end{array}$ \\
\hline
\end{tabular}

Fonte: Traduzido e adaptado pelos autores a partir de (FUJITA, 2011). 
The Dynamics of Local Learning in Global Value Chains: Uma Análise Crítica

Para analisar as capacidades tecnológicas dos fornecedores locais, Fujita desenvolveu, em linha com estudos anteriores sobre capacidades tecnológicas, (LALL, 1992), (ARIFFIN, 2000) e (FIGUEIREDO, 2008) interessante matriz, reproduzida na Figura 3, que classifica as áreas funcionais de acordo com o nível de capacidade atingido.

$\mathrm{O}$ autor, então, realizou estudos de caso em profundidade com 17 fornecedores vietnamitas de componentes de motocicletas, parte deles fornecedores de filiais de multinacionais japonesas e parte de montadoras de motos chinesas ou vietnamitas. As montadoras japonesas, basicamente Honda, Yamaha e Suzuki, são líderes mundiais na fabricação de produto e exercem maior controle de custo e qualidade do que as locais. Colocam muita ênfase no desenvolvimento de capacidade de produção e particularmente de gestão de produção, por parte de seus fornecedores. Exercem governança mais hierárquica do que as chinesas e vietnamitas.

Com base nos estudos de caso realizados, Fujita classificou as competências funcionais de cada fornecedor em operacional, assimilativo, adaptativo e inovador. O resultado dessa classificação está representado na Figura 4. Com base na classificação, o autor observa que os níveis de capacidade alcançados pelos fornecedores são surpreendentes (remarkable), ainda mais se considerado o curto intervalo de tempo que se passou entre o surgimento desses fornecedores e o momento da pesquisa, pouco mais de dez anos. Embora nenhuma das firmas tivesse alcançado o nível inovativo em nenhuma das quatro funções, várias tinham alcançado o assimilativo e mesmo o adaptativo.

Figura 4. Níveis de capacidade alcançados por fornecedoras de componentes de motocicletas do Vietnam em 2008

\begin{tabular}{|c|c|c|c|c|c|c|c|c|c|c|c|c|c|c|c|c|c|}
\hline \multirow{2}{*}{ Empresa } & \multirow{2}{*}{$\begin{array}{l}\text { Participação na } \\
\text { cadeia de valor } \\
\text { de motos }\end{array}$} & \multicolumn{4}{|c|}{ Planejamento } & \multicolumn{4}{|c|}{ Equipamentos } & \multicolumn{4}{|c|}{$\begin{array}{l}\text { Gestão de } \\
\text { produção }\end{array}$} & \multicolumn{4}{|c|}{ Marketing } \\
\hline & & $\begin{array}{l} \\
p \\
\end{array}$ & As & $\begin{array}{l}\mathrm{A} \\
\mathrm{d}\end{array}$ & In & $\begin{array}{l}\mathrm{O} \\
\mathrm{p}\end{array}$ & As & $\begin{array}{l}\mathrm{A} \\
\mathrm{d}\end{array}$ & In & $\begin{array}{l}\mathrm{O} \\
\mathrm{p}\end{array}$ & As & $\begin{array}{l}\mathrm{A} \\
\mathrm{d}\end{array}$ & In & $\begin{array}{l}\mathrm{O} \\
\mathrm{p}\end{array}$ & As & $\begin{array}{l}\text { A } \\
\mathrm{d}\end{array}$ & In \\
\hline $\mathrm{A}$ & $\mathrm{J}$ (1st tier) & & & & & & & & & & & & & & & & \\
\hline $\mathrm{B}$ & $\mathrm{J}$ (1st tier) & & & & & & & & & & & & & & & & \\
\hline $\mathrm{C}$ & $\mathrm{J}$ (1st tier) & & & & & & & & & & & & & & & & \\
\hline $\mathrm{D}$ & $\mathrm{J}$ (1st tier) & & & & & & & & & & & & & & & & \\
\hline $\mathrm{E}$ & $\mathrm{J}$ (1st tier) & & & & & & & & & & & & & & & & \\
\hline $\mathrm{F}$ & $\mathrm{J}$ (1st tier) & n.a. & & & & & & & & & & & & & & & \\
\hline $\mathrm{G}$ & $\mathrm{J}$ (2nd tier) & & & & & & & & & & & & & & & & \\
\hline $\mathrm{H}$ & $\mathrm{J}$ (2nd tier) & n.a. & & & & & & & & & & & & & & & \\
\hline $\mathrm{I}$ & $\mathrm{J}$ (2nd tier) & & & & & & & & & & & & & & & & \\
\hline $\mathrm{J}$ & $\mathrm{J}$ (2nd tier) & & & & & & & & & & & & & & & & \\
\hline $\mathrm{K}$ & $\mathrm{V}-\mathrm{C} \rightarrow \mathrm{J}(1$ st tier $)$ & & & & & & & & & & & & & & & & \\
\hline $\mathrm{L}$ & $\mathrm{V}-\mathrm{C} \rightarrow \mathrm{J}(2 \mathrm{nd}$ tier $)$ & & & & & & & & & & & & & & & & \\
\hline $\mathrm{M}$ & $\mathrm{V}-\mathrm{C} \rightarrow \mathrm{J}$ (2nd tier) & & & & & & & & & & & & & & & & \\
\hline $\mathrm{N}$ & $\mathrm{V}-\mathrm{C} \rightarrow \mathrm{J}(2 \mathrm{nd}$ tier $)$ & & & & & & & & & & & & & & & & \\
\hline $\mathrm{O}$ & $\mathrm{V}-\mathrm{C}$ & & & & & & & & & & & & & & & & \\
\hline $\mathrm{P}$ & $\mathrm{V}-\mathrm{C}$ & & & & & & & & & & & & & & & & \\
\hline $\mathrm{Q}$ & $\mathrm{V}-\mathrm{C}$ & & & & & & & & & & & & & & & & \\
\hline
\end{tabular}

Fonte: Fujita (2011, p. 89)

Nota: OP: Operacional; As: Assimilativo; Ad: Adaptativo; In: Inovativo

O autor também investigou os eventos de aprendizagem ocorridos nos 17 fornecedores. Definiu eventos de aprendizagem como sendo aqueles que envolveram ou o progresso de um nível de capacidade para outro, ou o progresso substancial dentro de um nível dado. Por exemplo, um evento de aprendizagem pode estar associado com o lançamento de novo produto ou tecnologia ou iniciativas para aumentar substancialmente a qualidade, custo ou tempo de entrega, em resposta a demanda de clientes. A Figura 5 sintetiza os achados a esse respeito. 
The Dynamics of Local Learning in Global Value Chains: Uma Análise Crítica

Figura 5. Classificação dos eventos de aprendizagem por função de capacidade adquirida

\begin{tabular}{|l|l|l|l|l|l|l|l|l|l|}
\hline & & \multicolumn{7}{|c|}{ Classificação por função } \\
\hline & & $\mathrm{N}$ & $\mathrm{N}$ & $\begin{array}{l}\text { Nível } \\
\text { atingido }\end{array}$ & $\mathrm{N}$ & $\begin{array}{l}\text { Nível } \\
\text { Máximo } \\
\text { atingido }\end{array}$ & $\begin{array}{l}\text { Nível } \\
\text { Máximo } \\
\text { atingido }\end{array}$ & N & $\begin{array}{l}\text { Nível } \\
\text { Máximo } \\
\text { atingido }\end{array}$ \\
\hline $\begin{array}{l}\text { Cadeias Japonesas } \\
1^{\circ} \text { Nível }\end{array}$ & 15 & 0 & - & 15 & Adaptativo & 15 & Adaptativo & 0 & - \\
\hline $\begin{array}{l}\text { Cadeias Japonesas } \\
2^{\circ} \text { Nível }\end{array}$ & 7 & 0 & - & 7 & Adaptativo & 7 & Assimilativo & 1 & Assimilativo \\
\hline $\begin{array}{l}\text { CadeiasVietnamita/ } \\
\text { Chinesa }\end{array}$ & 5 & 4 & Adaptativo & 3 & Operacional & 3 & Operacional & 1 & Assimilativo \\
\hline $\begin{array}{l}\text { Outras cadeias de } \\
\text { motocicleta }\end{array}$ & 3 & 0 & - & 3 & Assimilativo & 3 & Assimilativo & 0 & - \\
\hline Outras cadeias & 20 & 12 & Adaptativo & 18 & Adaptativo & 10 & Assimilativo & 5 & Adaptativo \\
\hline Total & 50 & & & & & & & & \\
\hline
\end{tabular}

Fonte: Fujita (2011, p. 91)

Nota: N: Número de eventos

O que a análise dos eventos de aprendizagem revela é que os fornecedores de montadoras japonesas, tanto as que fornecem conjuntos inteiros (first tier) como as que fornecem peças isoladas (2nd tier), tiveram mais eventos de aprendizagem ligados a equipamentos e gestão de produção do que os fornecedores de montadoras vietnamita e chinesa. Contudo, esses tiveram mais eventos e alcançaram maior nível de capacidade nas funções de planejamento e marketing. E os fornecedores que mais eventos de aprendizagem tiveram e maior nível de capacidade alcançaram, pincipalmente nas funções de planejamento e marketing, foram os que forneciam para outras cadeias, além da de motocicletas. Ou seja, firmas em cadeias de valor hierárquicas desenvolvem capacidade e aprendem mais nas funções ligadas à produção e menos nas ligadas a planejamento e marketing de produtos.

A principal contribuição da pesquisa que o autor destaca é que o nível de capacidade alcançado pela firma depende da estratégia de aprendizagem dela. Essa conclusão estaria suportada pelo fato de que diferentes firmas, mesmo dentro da mesma cadeia de valor, alcançaram diferentes níveis de capacidades $\mathrm{O}$ aumento de capacidade não é determinado pela governança da cadeia de valor, mas pela estratégia e determinação do fornecedor em ser bem-sucedido.
O que o autor não destaca é a semelhança entre os resultados que ele alcança e os que (HUMPHREY; SCHMITZ, 2002) e (NAVAS-ALEMÁN, 2011) já tinham alcançado anos antes: Que firmas que se inserem em cadeias globais mais fracamente governadas ou em várias cadeias simultaneamente, realizam mais upgrading funcional do que aquelas que se inserem em cadeias quase-hierárquicas. Estas ficam limitadas a fazerem upgrading de processo e eventualmente de produto, que em geral apropriam menos valor nas cadeias. A diferença é que enquanto Fujita centra sua análise em aprendizagem e capacidade, Navas-Alemán (2011) e Humphrey e Schimitz (2002) focam upgrading. A convergência entre os dois conceitos, upgrading e acumulação de capacidades tecnológicas, como definido na introdução por Kawakami e nesse capítulo por Fujita, também fica evidente.

No capítulo 4, Local firms capacity development in captive value chains: Evidence from Indonesian motorcycle industry, Yuri Sato, também pesquisador sênior do Jetro e coautor de Fujita em alguns trabalhos, realiza uma pesquisa semelhante a exposta no capítulo 3 quanto a indústria, métodos e em boa parte, chega a mesma conclusão. Faz um estudo de caso com 25 fornecedores de componentes para montadoras de motocicletas na Indonésia. O recurso metodológico 
The Dynamics of Local Learning in Global Value Chains: Uma Análise Crítica

central é a matriz de capacidades. A principal diferença entre os dois casos é que, na Indonésia, a fabricação de motos quase sempre foi dominada pelas filiais das fabricantes japonesas, que conseguiram desenvolver nesse país redes de fornecedores e distribuidores, portanto cadeias locais mais amplas e bem estabelecidas do que no Vietnam.

A Figura 6 resume os principais achados da pesquisa. Os números nas células representam o porcentual das firmas analisadas que alcançou aquele nível de desenvolvimento de capacidade naquela área funcional. Assim como no estudo de Fujita, a maior concentração é de firmas que acumularam capacidades na área da produção e nessa, nas atividades ligadas a gerência da produção. $\mathrm{O}$ resultado diferente que o autor destaca é que um porcentual não pequeno de firmas conseguiu alcançar o nível adaptativo de capacidade em pré-produção e marketing, mesmo estando inseridas numa cadeia fortemente coordenada. Isso demonstraria que, diferentemente do que o assumido em parte da literatura de $\mathrm{CGV}$, é possível alcançar esses níveis, o que significaria que a estratégia de aprendizado do fornecedor faz diferença.

Figura 6. Nível de capacidades das empresas locais em cadeias de valor cativas dos montadores japoneses

\begin{tabular}{|c|c|c|c|c|}
\hline Extensão & Pré-Produção & \multicolumn{2}{|c|}{ Produção } & Pós-Produção \\
\hline $\begin{array}{l}\text { Profundidade } \\
\text { (Nível) }\end{array}$ & Planejamento & $\begin{array}{l}\text { Relação com } \\
\text { Equipamentos }\end{array}$ & $\begin{array}{l}\text { Gestão de } \\
\text { Produção }\end{array}$ & Marketing \\
\hline Operacional & 12 & 96 & 96 & 88 \\
\hline Assimilativo & 0 & 62 & 84 & 0 \\
\hline Adaptativo & 8 & 4 & 24 & 12 \\
\hline Inovativo & 0 & 0 & 0 & 0 \\
\hline
\end{tabular}

Fonte: Traduzido de SATO (2011, p. 115)

No capítulo 5, To be or not to be a supplier to TNCs? An entrepreneurial approach to linkage formation in the Malaysian eletronics industry, (OIKAWA, 2011a), analisa como elementos de orientação empreendedora (OE) são construídos pelos fornecedores de empresas multinacionais estrangeiras (MNE) presentes no leste asiático (LA), mais especificamente na Malásia. Para ele, a análise dos determinantes de $\mathrm{OE}$ pode completar o modelo de Kawakami (2011) ao questionar se a estratégia dos fornecedores é importante para formação das capacidades e captação de valor, ou se, como apresentado por Gereffi et al (2005), este é um processo determinado pelo líder da CGV.

Oikawa (2011a) usa a definição e operacionalização de OE de (COVIN; SLEVIN, 1989) para comparar a intensidade dos elementos componentes da $\mathrm{OE}$ entre fornecedores de MNE e não MNE. Os elementos da OE que o autor usa na comparação são: orientação ao mercado, orientação para aprendizagem tecnológica, aceitação e tolerância ao risco e orientação autônoma. Usando evidências coletadas em entrevistas, o autor atribuiu escores de 1 a 5 para cada elemento da OE para cada empresa entrevistada e calculou a média do elemento para os dois grupos. O resultado da comparação é apresentado graficamente na Figura 7.

$\mathrm{O}$ autor conclui que os perfis dos empreendedores que optam por fornecer para MNE é diferente daqueles que escolhem fornecer para o mercado local. Os empreendedores que são mais orientados para a aprendizagem tecnológica e menos preocupados com a autonomia, e "que são indiferentes a permanecerem subservientes" (p. 163), optam por serem fornecedores de MNE. Os que têm maior tolerância a risco, preferem perseguir oportunidades no mercado local. 
Figura 7 - Determinantes da Orientação Empreendedora

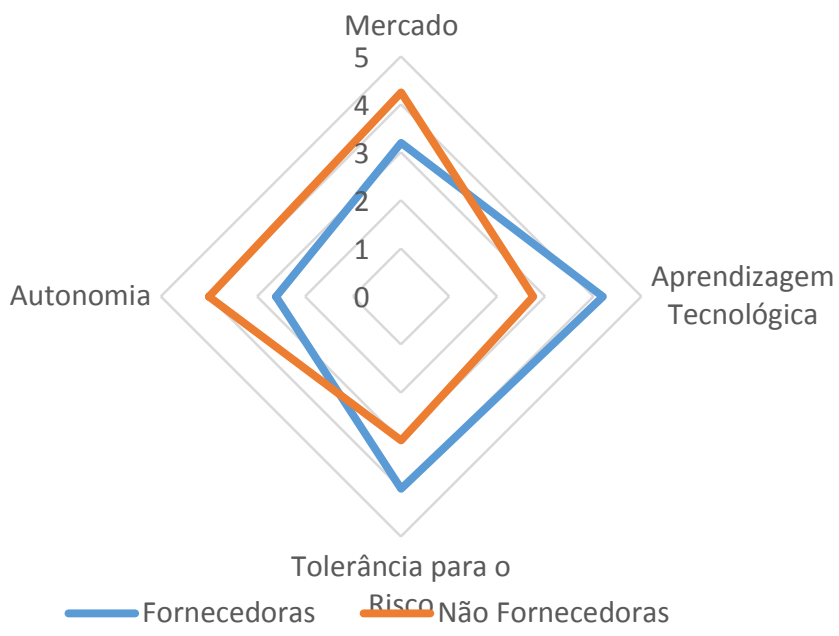

Fonte: Oikawa (2011a, p. 158)

Enquanto a tendência dos estudos em CGV e mesmo dos autores dos outros capítulos do livro, atribuem o engajamento das empresas locais em CGV ou cadeias locais, (OIKAWA, 2011a) sugere que o tipo de cadeia em que a firma se insere pode ser influenciada pela OE do empreendedor. A contribuição do autor é criativa e introduz uma variável nova na discussão. Porém seu estudo tem seu valor diminuído por duas limitações da metodologia: o pequeno tamanho da amostra e o fato dos valores atribuídos por ele aos elementos da $\mathrm{OE}$ dos entrevistados não terem sido submetidos a nenhum tipo de validação. Para uma pesquisa cuja validade está baseada nessa avaliação, o autor deveria ter pedido a outro pesquisador para também atribuir valores e calcular um índice de concordância, o inter-rater reliability entre as duas avaliações (ARMSTRONG et al., 1997).

No capítulo 6, Inter-Country Value Distribution in the East Asian Electronics and Automobile Industries: An Empirical Global Value Chain Approach, OIKAWA (2011b) discute se os ganhos de desenvolvimento econômico foram distribuídos igualmente entre os vários países do LA e chega à conclusão de que essa distribuição foi bastante desigual.

O autor analisa o desempenho das indústrias de eletrônicos e automóveis de vários países do LA baseando-se em dois índices: 1. O market-share da indústria do país no comércio internacional e 2 . O índice de valor distribuído dessas industrias (IVD) desses países. O IVD indica quanto o do valor é retido dentro da economia. Para calcular o IVD, o autor se vale de tabelas de entrada-saída internacional para o LA.

Para analisar a performance relativa do país na produção regional, Oikawa (2011b) criou uma classificação do desempenho com quatro categorias (Figura 8): 1. Ganhadores absolutos, os países que tiveram aumento de market share e do índice IVD; 2. Ganhadores substanciais, os que tiveram aumento IVD, mas redução de Market-share; 3. Ganhadores questionáveis, tiveram aumento de market share e redução de IVD e 4. Perdedores absolutos, os que tiveram redução de IVD e market share. 
The Dynamics of Local Learning in Global Value Chains: Uma Análise Crítica

Figura 8 - Matriz do desempenho da industrialização do Leste da Ásia

\begin{tabular}{|l|l|l|l|}
\cline { 3 - 4 } \multicolumn{2}{c|}{} & \multicolumn{2}{c|}{ Market Share Global } \\
\cline { 3 - 4 } \multicolumn{2}{c|}{} & \multicolumn{1}{c|}{ Aumentou } & \multicolumn{1}{c|}{ Reduziu } \\
\hline \multirow{3}{*}{ Índice IVD } & Aumentou & Ganhadores Absolutos & $\begin{array}{l}\text { Ganhadores } \\
\text { Substanciais }\end{array}$ \\
\cline { 2 - 4 } & Reduziu & $\begin{array}{l}\text { Ganhadores } \\
\text { Questionáveis }\end{array}$ & Perdedores Absolutos \\
\hline
\end{tabular}

Fonte: Traduzido de (OIKAWA, 2011b)

Como mostra a Figura 9, foram poucas as indústrias dos países do LA que se enquadraram na categoria de ganhadores absolutos, de acordo com critério definido por Oikawa. As análises revelam que, apesar da ampliação da participação nas exportações, as indústrias não conseguiram capturar valor agregado.

Figura 9-Matriz de desempenho da industrialização do Leste da Ásia

\begin{tabular}{|c|c|c|c|}
\hline & $\begin{array}{c}\text { Ganhadores } \\
\text { Absolutos }\end{array}$ & $\begin{array}{l}\text { Ganhadores } \\
\text { Questionáveis }\end{array}$ & $\begin{array}{c}\text { Perdedores } \\
\text { Absolutos }\end{array}$ \\
\hline Eletrônicos & - Indonésia & $\begin{array}{l}\text { - China } \\
\text { - Coréia } \\
\text { - Malásia } \\
\text { - Taiwan } \\
\text { - Filipinas } \\
\text { - Tailândia }\end{array}$ & - Japão \\
\hline Automobilístico & $\begin{array}{l}\text { - Indonésia } \\
\text { - Malásia } \\
\text { - Taiwan } \\
\text { - Tailândia }\end{array}$ & - & - \\
\hline
\end{tabular}

Fonte: Compilado pelos autores a partir dos resultados apresentados por OIKAWA (2011b)

Uma conclusão do seu estudo que o autor destaca é que o caminho para a industrialização que as economias do LA escolheram, baseado na atração e MNE, tem sido "menos do que bem-sucedido" (p. 185). Outra é que a Coreia e Taiwan têm sido melhor sucedidas na estratégia que adotaram, desenvolverem produtos com marcas. Essa estratégia é melhor sucedida, na opinião do autor, porque é menos dependente de investimento direto internacional. Contudo, o autor reconhece que a estratégia desses dois países, se bem que desejável, não pode ser facilmente replicável por países de industrialização tardia. Depende de capacidades avançadas e de investimentos pesados em componentes tecnológicos, recursos dos quais esses países normalmente são carentes.

\section{AVALIAÇÃO CRÍTICA}

\subsection{Pontos fortes}

O livro descreve uma série de experiências de setores do Leste da Ásia que conseguiram desenvolver capacidades tecnológicas. São experiências interessantes, que nos informam de indústrias, países e contextos sobre os quais pouco temos acesso e fazem refletir sobre semelhanças e diferenças entre esse contexto e o da América Latina, onde vivemos e pesquisamos.

A obra não é, como com frequência acontece em situações desse tipo, uma justaposição de artigos rapidamente elaborados para compor um tomo. Ele traz artigos que resumem experiências elaboradas com algum rigor metodológico, bem expostos e que, acima de tudo, se integram num todo harmônico, todos discutindo e argumentando as mesmas teses.

Apesar de que algumas conclusões que os capítulos do livro sugerem serem semelhantes aos que outros autores, com perspectivas ligeiramente diferentes já haviam chegado, como destacado no item 3 abaixo, o livro traz contribuições originas importantes. Ele dá ênfase à possibilidade de firmas inseridas em $\mathrm{CGV}$ fortemente coordenadas realizarem acumulação de capacidades tecnológicas se tiverem OE e se tiverem determinação e estratégias diferenciadas de aprendizagem. Ele oferece um modelo e uma gama de conceitos que permitem, mais do que os modelos existentes anteriormente, explicar diferenças de 
The Dynamics of Local Learning in Global Value Chains: Uma Análise Crítica

trajetórias na acumulação de capacidades tecnológicas e do sucesso, entre firmas inseridas na mesma CGV.

\subsection{Limitações}

Os capítulos do livro, não conseguem sustentar convincentemente a tese central dele, que o investimento estratégico e direcionado das firmas retardatárias é, de longe o fator mais importante em moldar o processo de aprendizagem dessas firmas. É apenas quando as firmas buscam explorar as oportunidades oferecidas pelas CGVs, e fazem investimentos substanciais na absorção de tecnológicas e conhecimento e na consolidação dos recursos adquiridos que essas firmas têm uma chance de elevar com sucesso as suas capacidades.

O modelo proposto é menos conciso do que o de Gereffi e também menos do que o diagrama da Figura 1, traduzida ao pé da letra do original, induz a crer. Duas "caixas" são compostas de duas variáveis: Complexidade/Codificabilidade são duas variáveis distintas e o mesmo acontece com ambiente institucional e condições locais.

Os conceitos de capacidade tecnológica terminam por ser bastante parecidos com os de upgrading. As conclusões a respeito das possibilidades de firmas de países de industrialização tardia que se inserem em CGV conseguirem ou não acumular capacidades tecnológicas trazidas pelos capítulos do livro se assemelham bastante às conclusões de vários autores da CGV sobre a possibilidade dessas firmas fazerem upgrading nas mesmas condições. Em algumas passagens os próprios autores usam os termos acumulação de capacidades tecnológicas e upgrading como sinônimos. Os Autores dos capítulos do livro sustentam que as firmas que estão inseridas em CGV fortemente coordenadas acumulam predominantemente capacidades nas áreas de produção, mas não de marketing. Para acumularem capacidades de marketing é uma condição importante elas e inserirem em múltiplas cadeias ou pelo menos cadeias menos fortemente coordenadas. Os autores que discutem a possibilidade de upgrading, sustentam que as firmas inseridas em $\mathrm{CGV}$ fortemente coordenadas fazem upgrading de processo e de produto, mas não funcional. Embora os conceitos não sejam exatamente os mesmos, as semelhanças são notórias.

\subsection{A quem o livro se destina}

O livro inteiro, ou capítulos do mesmo, pode ser importante para pesquisadores interessados em estratégia, em particular estratégia de internacionalização de empresas. Ele pode ser interessante tanto pelo modelo que propõe como pelos exemplos de setores e firmas que traz.
O livro também propicia uma interessante oportunidade de debate acadêmico, na medida em que contesta um modelo consagrado. Nesse sentido, ele pode ser usado por professores de cursos de pósgraduação, tanto estrito senso como lato, para mostrar como conclusões de pesquisas feitas com rigor podem se contrapor e incentivar alunos a discutirem e defenderem posições próprias.

Vários capítulos do livro também são úteis para pesquisadores como modelos de estruturação de estudos de casos múltiplos. O desenvolvimento dos capítulos que apresentam pesquisas empíricas é bem estruturado e os diagramas que sintetizam os dados são criativos e convincentes. Esses capítulos, apesar de serem estudos de casos, sistematizam os dados de forma que não se limita a textos e citações. Se aproxima de métodos mistos.

\subsection{Questões de pesquisa que o livro sugere}

O leitor atento do livro também encontrará nele sugestões explicitas e implícitas de questões de pesquisa que podem orientar dissertações de mestrado, teses de doutorado ou outras.

Uma questão que o Kawakami propõe na introdução e é pouco trabalhada no livro é: Como o surgimento de fornecedores competentes em países de industrialização tardia alterou as CGVs? Por exemplo: Como o surgimento de fornecedores de vinhos finos no Chile, Argentina, África do Sul, Austrália, entre outros países alterou a posição dos fornecedores tradicionais, essencialmente França e Itália? E como alterou a relação de poder e coordenação das CGV entre compradores e fornecedores?

O fato do livro não dar resposta suficiente a algumas questões que ele mesmo levanta, embora seja uma limitação do livro, oferece a possibilidade de outros pesquisadores fazerem isso. Por exemplo: $\mathrm{O}$ livro sugere que o fornecedor pode escapar às restrições impostas pelo coordenador da cadeia, se tiver forte $\mathrm{OE}$ e perseguir determinadamente estratégias de acumulação de capacidades. Como já expresso nessa resenha, a opinião dos autores dessa é que ele não traz exemplos convincentes disso. Essa limitação do livro é uma oportunidade de pesquisa. A realização de estudos de caso que sejam mais convincentes do que os do livro seria contribuição importante à pesquisa de CGV .

Finalmente, nenhum dos capítulos do livro realiza um estudo quantitativo das proposições do modelo exposto. Os oito construtos que compõem o modelo são perfeitamente passíveis de serem medidos através de escalas. Um estudo quantitativo que teste essas proposições também seria importante contribuição aos estudos de CGV. 


\section{REFERÊNCIAS}

Ariffin, N. (2000), The internationalisation of innovative capabilities: the Malaysian eletronics industry. [s.1.] University of Sussex.

Armstrong, D. Et al. (1997), The place of inter-rater reliability in qualitative research: an empirical study. Sociology, v. 31, n. 3, p. 597-606.

Covin, J. G.; Slevin, D. P. (1989), Strategic management of small firms in hostile and benign enviroments. Strategic management journal, v. 10, n. 1, p. $75-87$.

Figueiredo, P. N. (2008), Industrial policy changes and firm-level technological capability development: evidence from northern Brazil. World development, v. 36, n. 1, p. $55-88$.

Fujita, M. (2011). Value chain dynamics and local suppliers'capability building: an analysis of the vietnamese motorcycle industry. In: the dynamics of local learning in global value chains: experiences from East Asia. [s.l: s.n.].

Gereffi, G. (2014), A global value chain perspective on industrial policy and development in emerging markets. Duke journal of comparative \& international law, v. 24. P. 433-458.

Gereffi, G.; Fernandez-Stark, K. (2011), Global value chain analysis: a primer. Center on globalization, governance \& competitiveness (CGGC), Duke University. Durham, North Carolina, USA. Disponível em $<$ http://www.cggc.duke.edu/pdfs/2011-05-

31_gvc_analysis_a_primer.pdf $>$.

Gereffi, G.; Humphrey, J.; Sturgeon, T. (2005), The governance of global value chains. Review of international political economy, v. 12, n. 1, p. 78-104.

Humphrey, J.; Schmitz, H. (2004), Chain governance and upgrading: taking stock. In: local enterprises in the global economy. [s.l: s.n.]. V. 29p. 349-381.

Humphrey, J.; Schmitz, H. (2000), Governance and upgrading: linking industrial cluster and global value chain research. Ids working paper 120 . Brighton: institute of development studies.

Humphrey, J.; Schmitz, H. (2002), How does insertion in global value chains affect upgrading in industrial clusters? Regional studies.

Kaplinsky, R.; Morris, M. (2003), A handbook for value chain research. IDRC - International Development Research Center. Canadá. Dec. 2003. Disponível em:

Http://www.value-

chains.org/dyn/bds/bds2search.details2?p_phase_id=395\&p_lang= en\&p_phase_type_id=1.

Kawakami, M.; Sturgeon, T. (2011). The dynamics of local learning in global value chains. Palgrave Macmillan, $233 \mathrm{p}$.

Lall, S. (1992), Technological capabilities and industrialization. World development, v. 20, n. 2, p. 165-186.

Lamy, P. (2016), A conversation with Pascal Lamy - Duke global summit. Disponível em: <https://www.youtube.com/watch?v=d_rjq3sjrwa>.

Maclennan, M. L. F.; Avrichir, I.; Figueiredo, C. C. F. (2015), Exports and upgrading: evidences from a cluster in Brazil. International journal of business and emering markets.

Navas-Alemán, L. (2011), The impact of operating in multiple value chains for upgrading: the case of the brazilian furniture and footwear industries. World development, v. 39, n. 8, p. 1386-1397.

Oikawa, H. (2011a). To be or not to be na supplier to TNCs? An entrepreneurial approcah to linkage formation in the malasyan eletroics industry. In: The dynamics of local learning in global value chains: experiences from East Asia. New York: Palgrave Macmillan and IDE-JETRO. p. 136-166.

Oikawa, H. (2011b). Inter-country value distribution in the East Asian electronics and automobile industries: an empirical global value chain approach. In: the dynamics of local learning in global value chains. [s.1.] Springer. p. 167-206.

Sato, Y. (2011). Local firms capacity development in captive value chains: evidence from indonesian motorcycle industry. In: kawakami, m.; sturgeon, t. J. (eds.). . The dynamics of local learning in global value chains: experiences from east asia. New york: palgrave macmillan and IDEJETRO. p. 100-135.

Schmitz, H. (2005), Value chain analysis for policymakers and practitioners. Institute of development studies university of Sussex, England. Disponível em:

http://www.bdsknowledge.org/dyn/bds/docs/424/vca\%20gu ide\%20schmidt\%20ilo\%202005.pdf. 